Este libro forma parte del acervo de la Biblioteca Jurídica Virtual del Instituto de Investigaciones Jurídicas de la UNAM

\title{
LOS ESTADOS DE LA REGIÓN DE LAS AMÉRICAS: ESTRATEGIAS DE SALUD PÚBLICA Y PRINCIPIOS ÉTICOS ANTE LA PANDEMIA GOVID-19
}

\author{
Irene CÓRDOVA JIMÉNEZ \\ Rocío PRECiAdo GONZÁLEZ \\ Luis Alfonso Durán Montes
}

\begin{abstract}
Sumario: I. COVID-19. II. Datos globales. III. Región de las Américas. IV. Salud Pública. V. Ética, derecho y emergencias sanitarias. VI. Reglamento Sanitario Internacional. VII. Pacto de Siracusa y las limitaciones a derechos civiles. VIII. Comité de emergencia del RSI y el director general de la OMS. IX. Estrategias de salud pública en la región de las Américas. X. Principios éticos y estrategias de salud pública. XI. Conclusiones. XII. Fuentes de consulta.
\end{abstract}

\section{COVID-19}

Las pandemias representan problemas en salud de gravedad y repercusiones tales que ponen en riesgo la salud pública internacional. Las más recientes, como el síndrome respiratorio agudo grave (SARS por sus siglas en inglés: Severe Acute Respiratory Syndrome) en 2012 y la influenza H1N1 en 2009, han recordado a los países la necesidad de que sus gobiernos estén preparados para responder adecuada y oportunamente ante situaciones de emergencias sanitarias, pues de lo contrario el impacto negativo se puede traducir en afectación a la salud de los individuos e incluso la muerte, pero también en debilitamiento de su economía. Los pilares de una gestión efectiva ante cualquier pandemia se encuentran en las decisiones informadas e informables y los procedimientos o protocolos de acción que mantengan un equilibrio ante la potencialidad de afectación a los derechos proporcionales, y las acciones ejecutadas que deben implementar las autoridades de cada país. Sin reglas bien establecidas y sólidas, las medidas que se planteen podrían resultar ineficaces, injustas, desproporcionadas y/o contraproducentes. 
Este libro forma parte del acervo de la Biblioteca Jurídica Virtual del Instituto de Investigaciones Jurídicas de la UNAM

El 31 de diciembre de $2019^{1}$ se detectan en la comunidad de Wuhan, China, los primeros casos que dieron origen al brote de una nueva enfermedad respiratoria denominada originalmente COVID-19, contra la cual, hasta la fecha, no se cuenta con tratamiento eficaz ni vacunas. Este virus ha mostrado un comportamiento agresivo en cuanto a su potencialidad de contagio y mortalidad. ${ }^{2}$

\section{DATOS GLOBALES}

Al 22 de junio de 2020, se han confirmado 9 millones 71 mil 984 casos, de los cuales han muerto 471 mil 554 personas en todo el mundo, el país con más casos confirmados es Estados Unidos; México se encuentra en esta fecha en el lugar 15 (Tabla 1).

\section{TABla 1. PRINCIPALES PAíses POR NÚMERO DE GASOS Y NÚMERO DE DEFUNCIONES POR COVID-19, CONFIRMADOS AL 20 DE JUNIO DE $2020^{3}$}

\begin{tabular}{|c|l|c|c|}
\hline & & Casos & Defunciones \\
\hline 1 & EUA & $2 ’ 310,798$ & 120,393 \\
\hline 2 & Brasil & $1 ' 106,470$ & 51,271 \\
\hline 3 & Rusia & 591,465 & 8,196 \\
\hline 4 & India & 425,282 & 13,699 \\
\hline 5 & UK & 306,761 & 42,731 \\
\hline 6 & España & 246,504 & 28,324 \\
\hline 7 & Perú & 257,447 & 8,223 \\
\hline 8 & Italia & 238,720 & 34,657 \\
\hline 9 & Chile & 246,963 & 4,502 \\
\hline
\end{tabular}

1 Organización Mundial de la Salud. Brote de enfermedad por coronavirus (COVID 19), disponible en: https://wwrw.who.int/es/emergencies/diseases/novel-coronavirus-2019? gclid=EAI aIQobChMIyoad_o6W6gIVwpfbCh1towIaEAATASAAEgK9DvD_BwE.

2 Río Carlos del y Malani Preetl, "COVID-19, New Insights on a Rapidly Changing Epidemic”, Fama, 2020, núm. 14, vol. 323, pp. 1341-1343.

3 Johns Hopkins University \& Medicine. Cronavirus Resouce Center. COVID-19 Dashboard by the Center for Systems Science and Engineering (CSSE) at Johns Hopkins University (JHU), disponible en: https://coronavirus.jhu.edu/map.html. 
Este libro forma parte del acervo de la Biblioteca Jurídica Virtual del Instituto de Investigaciones Jurídicas de la UNAM

\begin{tabular}{|c|l|c|c|}
\hline & & Casos & Defunciones \\
\hline 10 & Irán & 207,525 & 9,742 \\
\hline 11 & Francia & 207,525 & 29,666 \\
\hline 12 & Alemania & 191,768 & 8,999 \\
\hline 13 & Turquía & 188,897 & 4,974 \\
\hline 14 & Paquistán & 181,088 & 3,590 \\
\hline 15 & México & 185,122 & 22,584 \\
\hline 21 & China & 84,610 & 4,639 \\
\hline
\end{tabular}

\section{REGIÓN DE LAS AMÉRICAS}

Los Estados Miembros de la Organización Mundial de la Salud (OMS) están agrupados en 6 Regiones: África, las Américas, Asia Sudoriental, Europa, el Mediterráneo Oriental y el Pacífico Occidental. La región de las Américas concentra 49 países en el Norte, Centro y Sur de América y los países del Caribe. Hasta el 22 de junio se registraban en esta región 4 millones 474 mil 652 casos confirmados y 226 mil 634 defunciones por COVID-19 (Tabla 2).

TABla 2. Total DE PAÍSES DE LA REGión DE LAS AMÉRICAS DE LA OMS POR NÚMERO DE CASOS Y NÚMERO DE DEFUNCIONES POR COVID-19 CONFIRMADOS AL 22 DE JUNIO DE 2020

\begin{tabular}{|c|l|c|c|}
\hline Subregión & \multicolumn{1}{|c|}{ Países } & Casos & Defunciones \\
\hline C & Panamá & 26,030 & 501 \\
\hline G & Guatemala & 13,145 & 531 \\
\hline C & Honduras & 12,769 & 363 \\
\hline C & El Salvador & 4,808 & 107 \\
\hline G & Costa Rica & 2,277 & 12 \\
\hline G & Belice & 22 & 2 \\
\hline CA & República Dominicana & 27,370 & 669 \\
\hline CA & Puerto Rico & 6,564 & 149 \\
\hline CA & Haití & 5,211 & 88 \\
\hline CA & Guyana Francesa & 2,458 & 8 \\
\hline
\end{tabular}


Este libro forma parte del acervo de la Biblioteca Jurídica Virtual del Instituto de Investigaciones Jurídicas de la UNAM

\begin{tabular}{|c|c|c|c|}
\hline Subregión & Países & Casos & Defunciones \\
\hline CA & Cuba & 2,315 & 85 \\
\hline CA & Jamaica & 659 & 10 \\
\hline CA & Suriname & 319 & 8 \\
\hline CA & Martinica & 236 & 14 \\
\hline CA & Guyana & 205 & 12 \\
\hline CA & Islas Caimán & 195 & 1 \\
\hline CA & Guadalupe & 174 & 14 \\
\hline CA & Bermuda & 146 & 9 \\
\hline CA & Trinidad y Tabago & 123 & 8 \\
\hline CA & Sint Maarten & 114 & 18 \\
\hline CA & Bahamas & 104 & 11 \\
\hline CA & Aruba & 101 & 3 \\
\hline CA & Barbados y Caribe Oriental & 97 & 7 \\
\hline CA & Islas Vírgenes & 76 & 3 \\
\hline CA & San Vicente y las Grenadinas & 29 & 0 \\
\hline CA & Antigua y Barbuda & 26 & 3 \\
\hline CA & Curaçao & 23 & 1 \\
\hline CA & Granada & 23 & 0 \\
\hline CA & Santa Lucía & 19 & 0 \\
\hline CA & Dominica & 18 & 0 \\
\hline CA & Saint Kitts y Nevis & 15 & 0 \\
\hline CA & Islas Turcas y Caicos & 14 & 1 \\
\hline CA & Montserrat & 11 & 1 \\
\hline CA & Islas Vírgenes Británicas & 8 & 1 \\
\hline CA & Anguila & 3 & 0 \\
\hline $\mathrm{N}$ & Estados Unidos de América & $2 ’ 305,950$ & 120,393 \\
\hline $\mathrm{N}$ & México & 180,545 & 22,584 \\
\hline $\mathrm{N}$ & Canadá & 103,354 & 8,494 \\
\hline $\mathrm{S}$ & Perú & 257,447 & 8,223 \\
\hline $\mathrm{S}$ & Chile & 246,963 & 4,502 \\
\hline $\mathrm{S}$ & Brasil & $1^{\prime} 083,341$ & 51,271 \\
\hline
\end{tabular}


Este libro forma parte del acervo de la Biblioteca Jurídica Virtual del Instituto de Investigaciones Jurídicas de la UNAM

\begin{tabular}{|c|l|c|c|}
\hline Subregión & \multicolumn{1}{|c|}{ Países } & Casos & Defunciones \\
\hline S & Colombia & 68,836 & 2,353 \\
\hline S & Ecuador & 50,640 & 4,223 \\
\hline S & Argentina & 42,785 & 1,043 \\
\hline S & Bolivia & 24,388 & 773 \\
\hline S & Venezuela (República Bolivariana de) & 3,917 & 33 \\
\hline S & Nicaragua & 1,823 & 64 \\
\hline S & Paraguay & 1,392 & 13 \\
\hline S & Uruguay & 876 & 25 \\
\hline
\end{tabular}

Fuente: ${ }^{4} \mathrm{C}=\mathrm{El}$ Caribe, $\mathrm{CA}=$ Centroamérica, $\mathrm{N}=$ Norteamérica, $\mathrm{S}=$ Sudamérica .

Las cifras anteriores corresponden al 49.3\% de los casos de COVID-19 y el $48 \%$ de las muertes frente al número total de casos en el mundo. México ocupa el quinto lugar por casos confirmados y el tercero en número de muertes de entre los países de la región.

\section{SALUD PÚBLICA}

Una característica de las pandemias es la incertidumbre, misma que produce efectos diferenciados para cada país; estos, a su vez, impactan globalmente. En principio, la capacidad de respuesta de los diferentes sistemas de salud y sus ambientes culturales, educativos y económicos podrían ser una explicación de estas diferencias, aunque el caso de Estados Unidos de América (EUA) se aparta de esta afirmación. La salud pública, tanto disciplina como responsabilidad del Estado, debe posibilitar la respuesta eficiente y oportuna a las necesidades de salud (en ocasiones extremas) de una colectividad. En esta ocasión la gravedad del problema propio de la pandemia y las características del virus, unida a la incertidumbre, hacen más compleja la toma de las decisiones públicas para los gobiernos. A nivel social, podrían desanimar a los individuos, en quienes por cierto también recae la responsabilidad de la salud colectiva, a mantener algunas de las medidas de prevención más aconsejables. Es una respuesta imperiosa pero compleja, pues para que la población se comprometa es indispensable la confianza en sus gobiernos, de lo que algunos países de nuestra región adolecen.

\section{Idem.}


Este libro forma parte del acervo de la Biblioteca Jurídica Virtual del Instituto de Investigaciones Jurídicas de la UNAM

Los retos públicos que representa esta pandemia implican una respuesta de proporcionalidad entre las restricciones a la libertad de las personas, la afectación a la economía (la privada y la pública), y los límites de acceso a servicios de salud limitados y potencialmente insuficientes. Por lo anterior, los instrumentos éticos y legales, ya sean normativos o programáticos, son indispensables para la orientación de las acciones del Estado y de las poblaciones mundiales.

\section{V. ÉTICA, DERECHO Y EMERGENCIAS SANITARIAS}

Dada la situación actual, disposiciones oficiales emitidas en los Estados de la región para controlar y contener la pandemia por COVID-19, tales como el distanciamiento social y la cuarentena voluntaria u obligatoria; el cierre de escuelas y centros laborales; y la suspensión de actividades económicas no esenciales, han mostrado ser efectivas. La proporcionalidad de algunas otras disposiciones, como los estados de excepción y el toque de queda, podrían ser contrastadas con su eficacia, y en su caso, cuestionadas. Al mismo tiempo, la oportunidad y duración de estas disposiciones han permitido evidenciar la fragilidad de determinados grupos sociales, o el grado de responsabilidad de algunos otros. Los lapsos prolongados de suspensión de actividades o estados de cuarentena han demostrado que dichas medidas se relajan con el paso del tiempo debido a necesidades reales, como es el caso de los trabajadores independientes y sus necesidades económicas; o percibidas, para atender actividades lúdicas, por ejemplo.

Durante el curso clínico de la enfermedad por COVID-19, el número de individuos que llegan a necesitar atención en terapia intensiva y/o recursos de salud limitados, han rebasado la capacidad de respuesta en algunos de los países afectados, lo que ha planteado un verdadero reto en cuanto a la asignación de estos recursos. ${ }^{5}$ Del mismo modo, la atención a las necesidades específicas de algunos sectores de la población, como la protección al personal de salud durante el desempeño de sus labores, muestra una especie de vacío legal y normativo que no han logrado subsanar los propios sistemas de salud. ${ }^{6}$

La pandemia por el COVID 19 ha creado desafios éticos, legales y políticos que no tienen precedentes. El impacto de la salud pública sobre aspec-

5 Lissardy, Gerardo, "Coronavirus: el drama del COVID-19 en Nueva York, una ciudad con las morgues repletas y hospitales de campaña", BBC Newes, 8 de abril de 2020, disponible en: https://wrere.bbc.com/mundo/noticias-internacional-52211307.

6 Devi, Sharmila, "COVID-19 exacerbates violence against Health Workers", The Lancet, 5 de septiembre de 2020, núm. 10252, vol. 396, p. 658. 
Este libro forma parte del acervo de la Biblioteca Jurídica Virtual del Instituto de Investigaciones Jurídicas de la UNAM

tos sociales, tales como la justicia y la seguridad, fundamentan el imperativo de que las estrategias en salud pública se construyan con referentes éticos sólidos. Esta responsabilidad recae principalmente en los poderes públicos del Estado. Así, la emisión de sus disposiciones legales para atender la emergencia sanitaria presenta un primer desafío para los gobiernos de los Estados: tomar las decisiones oportunas, eficaces, justas y equitativas que posibiliten la atención a las necesidades de la población y controlen la pandemia, con los menores costos en salud, económicos y sociales.

Así, durante la pandemia por COVID-19, las decisiones éticas en salud pública deberían atender a un procedimiento que dé respuesta a preguntas tales como: ¿cuáles son las atribuciones de la autoridad para la emisión de las disposiciones legales excepcionales? ¿Guál es la proporcionalidad de las estrategias de limitación de las libertades en este contexto? ¿Cuál es el curso de acción que produce el mejor balance costo social/beneficio en salud pública? ¿Cuáles son los riesgos, daños o preocupaciones en la población? ¿Qué aspectos del contexto socio-cultural-histórico están implicados? ¿Cómo comunicar las decisiones públicas y permitir acceder fácilmente a las disposiciones legales? ¿Cuál es la mejor estrategia de gobernanza y liderazgo?

\section{REgLAMENTO SANITARIO INTERNACIONAL}

La OMS ejerce un liderazgo de orientación para que los Estados miembros realicen acciones dirigidas a limitar y tratar de evitar, entre otros, la propagación de enfermedades infecciosas y su impacto en las sociedades. La Asamblea Mundial de este organismo internacional tiene facultades para emitir reglamentos que contribuyan a lograr el objetivo mencionado.

En 1969 la Asamblea Mundial aprueba la primera versión del Reglamento Sanitario Internacional (RSI) y actualmente se encuentra vigente la versión del 2005. ${ }^{7}$ Los diferentes fenómenos de salud tuvieron impacto para favorecer diversos cambios y actualizaciones a este reglamento, particularmente la aparición del SARS declarada como la primera emergencia de salud pública mundial del siglo XXI. De conformidad con lo que dispone el artículo 2o., la finalidad y alcance del RSI son prevenir, proteger y controlar la propagación de enfermedades mediante respuestas de salud pública proporcionales a los riesgos. Dichas acciones propuestas deben evitar interferencias innecesarias con el tráfico y comercio internacional.

7 El RSI 2005 fue aprobado por la Asamblea Mundial de la OMS el 23 de mayo de 2005, entro en vigor el 15 de junio de 2007. 
Este libro forma parte del acervo de la Biblioteca Jurídica Virtual del Instituto de Investigaciones Jurídicas de la UNAM

Así, derivado de lo que dispone este reglamento los Estado Parte, deben establecer un Centro Nacional de Enlace para aplicar las medidas relacionadas con las disposiciones del RSI para, entre otras cosas, declarar emergencias de salud pública de importancia internacional.

De acuerdo con el RSI, tratándose de emergencias sanitarias Internacionales hay acciones fundamentales: ${ }^{8}$

a) La primera le corresponde a la OMS, reconocer la emergencia sanitaria internacional y con ello emitir directrices de apoyo a los Estados Partes para dar respuesta al problema de salud pública, y

b) La segunda que corre a cargo de los Estados Partes es la obligación de establecer, aplicar y mantener un Plan Nacional de Respuesta a Emergencias de Salud Pública que sean de importancia internacional.

El propósito clave de la existencia de estos planes es establecer acciones multidisciplinarias, coordinadas, sustentadas en evidencia científica, para evitar la discrecionalidad y la improvisación que requiere toda emergencia de salud pública. Desde otra perspectiva, este reglamento busca de igual forma establecer la rectoría de las acciones, tanto a nivel internacional como a nivel de un ente coordinador en cada Estado Parte.

\section{PACTO DE SiRAGUSA Y LAS LiMITAGiONES A DERECHOS GIVILES}

En 1984 se suscribe en el Consejo Económico y Social de la Organización de las Naciones Unidas los Principios de Siracusa sobre las disposiciones de limitación y derogación del Pacto Internacional de Derechos Civiles y Políticos. ${ }^{9}$ El documento supone la posibilidad de limitar derechos, pero bajo determinadas restricciones: ${ }^{10}$

a) Se base en uno de los motivos que justifican las limitaciones (las emergencias de salud pública lo son $\left.{ }^{11}\right)$;

b) Responda a una necesidad pública o social apremiante;

\footnotetext{
8 Organización Mundial de la Salud, "Reglamento Sanitario", OMS, Ginebra, 2016.

9 Consejo Económico y Social de la Organización de las Naciones Unidas, "Pacto de Siracusa", Comisión de Derechos Humanos, 28 de septiembre de 1984, 41 periodo de sesiones, tema 18, disponible en: https://undocs.org/pdf?symbol=es/E/CN.4/1985/4.

10 Punto 10 del apartado A. Parte I. del Pacto de Siracusa.

11 Artículos 15 y 16 del Pacto de Siracusa.
} 
Este libro forma parte del acervo de la Biblioteca Jurídica Virtual del Instituto de Investigaciones Jurídicas de la UNAM

c) Responda a un objetivo legítimo, y

d) Guarde proporción con dicho objetivo.

En los casos de emergencias de salud pública de interés internacional, la limitación a los derechos debe derivar de evaluaciones objetivas; en el caso de esta pandemia, debería ser la mejor evidencia científica disponible.

Respecto de esta emergencia sanitaria la OMS ha expresado que las restricciones de derechos humanos como consecuencia de las acciones de atención a la emergencia deben apegarse a la no arbitrariedad, a la legalidad, a justificar la necesidad de la medida, ser proporcionales y evitar la discriminación. ${ }^{12}$

Dada la historia de las emergencias de salud pública internacional y de los elementos constitutivos de esta pandemia, las acciones implementadas constituyen limitaciones parciales a dichos derechos. En casos extremos algunos Estados miembros han recurrido a los estados de excepción (o por ejemplo algunos denominándoles toques de queda), figura jurídica que ha sido debidamente definida por el derecho internacional. ${ }^{13}$ El reto en estos casos es valorar la proporcionalidad y la necesidad de la medida.

\section{COMITÉ DE EMERGENCIA DEL RSI Y EL DIRECTOR GENERAL DE LA OMS}

En su sesión del Comité de Emergencia del día 30 de enero de 2020, se consideró que se cumplían los criterios para declarar al COVID-19 como emergencia de salud pública de interés Internacional, ${ }^{14}$ se emitieron también recomendaciones para los Estados miembro consistentes en:

a) Prepararse para la contención, vigilancia activa, detección temprana, aislamiento y gestión de datos;

b) Compartir datos completos de casos a la OMS;

12 Oficina del Alto Comisionado de las Naciones Unidas, "Las medidas de emergencia y el COVID-19: Orientaciones", 27 de abril de 2020, disponible en: https://wrwrohchrorg/ Documents/Events/EmergencyMeasures_COVID19_ES.pdf.

13 Parte II del Pacto de Siracusa.

14 Organización Mundial de la Salud. Declaración sobre la segunda reunión del Comité de Emergencias del Reglamento Sanitario Internacional (2005) acerca del brote del Nuevo Coronavirus, 30 de enero de 2020, disponible en: https://wrwrewho.int/es/news-room/detail/3001-2020-statement-on-the-second-meeting-of-the-international-health-regulations-(2005)-emergency-committee-regarding-the-outbreak-of-novel-coronavirus-(2019-ncov). 
Este libro forma parte del acervo de la Biblioteca Jurídica Virtual del Instituto de Investigaciones Jurídicas de la UNAM

c) No restringir viajes o acciones de comercio;

d) Informar a la OMS si llegaran a tomar medidas de restricción de viajes.

El día 11 de marzo el director general de la OMS, Tedros Adhanom Ghebreyesus, reconoció finalmente la existencia de la pandemia COVID-19. Las recomendaciones iniciales se ampliaron en la tercera reunión del Comité celebrada el 30 de abril destacando las siguientes: ${ }^{15}$

a) Dimensionar las posibles consecuencias de COVID-19 haciendo hincapié en la necesidad de mayor preparación intersectorial, transparencia y coordinación global;

b) Incrementar la capacidad de aplicar pruebas de diagnóstico;

c) No restringir viajes esenciales: atención de la pandemia, repatriaciones, ayuda humanitaria, por ejemplo;

d) Apoyar el liderazgo de la OMS;

e) Prioriza la protección de la fuerza laboral de salud (capacitación y provisión de equipos de protección personal, mejores condiciones de trabajo y prevención de estigma y ataques contra los trabajadores de la salud).

\section{ESTRATEGIAS DE SALUD PÚBLICA EN LA REGIÓN \\ DE LAS AMÉRICAS}

El objetivo de este documento fue identificar las diferentes estrategias en salud pública que los Estados de la Región de las Américas (ERA) implementaron para la atención de los problemas derivados de la pandemia COVID-19 y su relación con principios éticos.

Para lo anterior se realizó una búsqueda exhaustiva de los documentos emitidos por los ERA a través de los cuales establecen medidas tales como: declaración de emergencia, aislamiento social y cuarentenas, control de fronteras suspensión de actividades presenciales educativas, suspensión de actividades comerciales, acceso a servicios de diagnósticos y de atención médica, distribución de recursos en medicina crítica, estrategias de comunicación a la sociedad y protección del personal de salud.

15 Organización Mundial de la Salud. Declaración sobre la tercera reunión del Comité de Emergencias del Reglamento Sanitario Internacional (2005) acerca del brote de enfermedad por coronavirus (COVID-19), 1o. de mayo de 2020, disponible en: https://wrere.who. int/es/newes-room/detail/01-05-2020-statement-on-the-third-meeting-of-the-international-health-regula tions-(2005)-emergency-committee-regarding-the-outbreak-of-coronavirus-disease-(covid-19). 
Este libro forma parte del acervo de la Biblioteca Jurídica Virtual del Instituto de Investigaciones Jurídicas de la UNAM

Se recabó en una matriz información relativa a estrategias de salud pública implementadas por los Estados miembros de la región de las Américas, las cuales fueron seleccionadas como variables a partir de disposiciones del RSI, del Pacto de Siracusa y/o de las recomendaciones del Comité de Emergencias de la Organización Panamericana de la Salud (OPS). Se registró información sobre la existencia o inexistencia de dichas estrategias, y sus fechas de emisión respecto de los primeros casos confirmados.

La información respecto de los casos activos y defunciones se obtuvieron del Centro de Recursos sobre Coronavirus de la Universidad Johns Hopkins, las fechas y los documentos que respaldan las estrategias de los Estados miembros fueron buscados en las páginas oficiales de cada uno de los países.

De los 49 que conforman la región, 12 países no reportan en sus páginas oficiales información sobre disposiciones legales, éticas, públicas o de cualquier otro tipo sobre acciones contra COVID-19, ${ }^{16}$ la mayoría de estos países pertenecen a la región del Caribe. El caso más relevante en las Américas sobre ausencia de información es Nicaragua, pues no se puede acceder a la página de la Presidencia. La información disponible sobre este país se encuentra en prensa, lo cual cuestiona los datos y el manejo de la crisis en Nicaragua. Así que se reporta exclusivamente la información de 37 países.

El primer caso confirmado en la región fue en EUA el 20 de enero. Canadá confirmó su primer caso el 25 de enero. Confirmaron su primer caso en febrero Brasil (26), México (28) y Ecuador (29), los 32 restantes confirmaron casos en marzo.

Las declaratorias de emergencia son los documentos públicos que detonan las acciones relativas a la contención y atención de la pandemia. Brasil fue el primer país de la región en emitir su declaratoria 23 días antes de que se confirmara su primer caso. Curaçao emitió la propia el 22 de febrero, 22 días antes de su primer caso. En total nueve países declararon la emergencia sanitaria antes de su primer caso. 12 países declararon la emergencia entre el 11 y el 17 de marzo (en la primera semana de la Declaración del Comité de Emergencias de la OMS del 11 de marzo). De los cuatro países que emitieron su declaratoria de forma posterior, tardando incluso más de 15 días después de su primer caso, destaca EUA con 53 días. ${ }^{17}$

16 Los países que se excluyen de este estudio son Guadalupe, Guyana, Guyana Francesa, Haití, Islas Vírgenes Británicas, Martinica, Montserrat, Nicaragua, San Vicente y las Grenadinas, Sint Maarten y Suriname.

17 En Estados Unidos se confirmó su primer caso el 29 de febrero de 2020, pero su declaratoria de emergencia se emitió hasta el 11 de marzo. 
Este libro forma parte del acervo de la Biblioteca Jurídica Virtual del Instituto de Investigaciones Jurídicas de la UNAM

Como se mencionó anteriormente, los Estados miembros se comprometieron a dar cumplimiento al RSI y con ello a contar con un Plan Nacional de Respuesta de Emergencias en Salud Pública. Solamente 15 países contaban con dicho plan, ya sea como ley nacional o como instrumento programático. 22 países no cuentan con este documento y tal vez por ello han recurrido a la emisión de actas, acuerdos, decretos, resoluciones de manera emergente y por rubros específicos. México es uno de esos países que no cuentan con el plan.

Cuarentena y aislamiento significan restricción de actividades y/o la separación de personas, con la intención de prevenir la propagación de la infección o contaminación. En el primer caso se refiere a personas enfermas o con sospecha de la enfermedad, en el segundo caso se refiere a la separación de personas sanas (como son las acciones de distanciamiento social y aislamiento en domicilio). $\mathrm{Al}$ respecto, los Estados de la región han emitido disposiciones en ambos sentidos, algunos con carácter obligatorio y otros dejando a las personas la opción de atender la disposición.

\begin{tabular}{|l|c|c|}
\hline & \multicolumn{2}{|c|}{ Número de países } \\
\hline & Obligatoria & Voluntaria \\
\hline Cuarentena & 16 & 21 \\
\hline Aislamiento & 11 & 25 \\
\hline
\end{tabular}

Ahora bien, en cuanto a la obligatoriedad de estas medidas, ningunas se emitieron de forma absolutas, todas presentaban excepciones; por ejemplo, salidas a consultas médicas o adquisición de bienes básicos.

El caso de EUA es especial y no se cuenta en ninguno de los supuestos anteriores, pues por lo general los Centros para el Control y Prevención de Enfermedades (CDC, por sus siglas en inglés) emite recomendaciones y los estados son autónomos para implementar las recomendaciones de este centro.

Ahora bien, en cuanto a la obligatoriedad de estas medidas, ninguna se emitió de forma absoluta, todas presentaban excepciones, por ejemplo, salidas a consultas médicas o adquisición de bienes básicos.

Independientemente de lo anterior, es posible encontrar documentos emitidos por 22 países en los que se menciona estado de excepción o toque de queda. Ciertamente con aclaraciones de los límites de estas declaraciones (horarios o regiones). No se define en dichas disposiciones lo que es un estado de excepción o un toque de queda. El incumplimiento en algunos casos conlleva multas, mientras en otros se puede hacer uso de la fuerza pública 
Este libro forma parte del acervo de la Biblioteca Jurídica Virtual del Instituto de Investigaciones Jurídicas de la UNAM

o la detención de las personas. Honduras es un caso especial pues estableció "Toque de queda absoluto con suspensión de garantías constitucionales desde el 16 de marzo y hasta nuevo aviso", ${ }^{18}$ lo que es contrario al Pacto de Siracusa.

Las recomendaciones de la OMS respecto a las pruebas de detección se relacionan con su acceso, sin embargo, nueve países han emitido disposiciones legales para que las autoridades tengan el derecho de obligar a sus habitantes a realizarse las pruebas de detección.

34 países han suspendido mediante documentos legales las actividades escolares, todos entre el 11 y el 25 de marzo, solo dos países lo han hecho de manera parcial (Santa Lucía e Islas Caimán). EUA no ha suspendido desde la rectoría federal las actividades educativas pues como en casos anteriores los Estados de la Unión Americana son autónomos para seguir o no las recomendaciones de los CDC. Aun sin una disposición federal al respecto, la suspensión de actividades escolares en EUA se llevó a cabo y se fue presentando en diferentes fechas.

33 países han emitido suspensión de actividades laborales estatales no esenciales, Santa Lucía y Trinidad y Tobago no suspendieron actividades y no se pudo tener conocimiento de información de este tipo de Bahamas y Venezuela.

La restricción o limitación de actividades privadas (económicas o recreativas) se presentaron en 31 países, la gran mayoría (27) a partir del 11 de marzo emitieron disposiciones de suspensión de actividades económicas privadas. No se encontró información pública en 6 países.

La limitación o restricción de paso fronterizo se estableció en algún momento y de manera absoluta en 15 países, la mayoría se trata de países de El Caribe cuya principal vía de acceso es marítima, 22 establecieron restricciones selectivas, por ejemplo, la limitación de ingreso de naves de países con mayor número de contagiados o la libertad de ingreso por repatriaciones.

Pese a la recomendación de la OMS para que los Estados miembros priorizaran la protección de la fuerza laboral de salud (capacitación y provisión de equipos de protección personal, mejores condiciones de trabajo y prevención de estigma y ataques contra los trabajadores $)^{19}$ solo 15 países

18 Este texto se publica como comunicado de prensa del Gobierno de la República de Honduras y de la Secretaría de Seguridad, disponible en: https://covid19honduras. org/?q=node/404, y se relaciona con el Decreto Ejecutivo núm. PGM-021-2020 emitido por la presidencia del país publicado en el Diario Oficial La Gaceta el 16 de marzo de 2020: disponible en: https://presidencia.gob.hn/index.php/sala-de-prensa/7016-decreto-ejecutivo-numero-pcm $-021-2020$.

19 Comité de Emergencia del RSI de la OMS del 30 de abril de 2020. 
Este libro forma parte del acervo de la Biblioteca Jurídica Virtual del Instituto de Investigaciones Jurídicas de la UNAM

emitieron mecanismos para la protección del personal de salud, aunque no necesariamente su seguridad, de los 22 países restantes no se cuenta con la información por las vías oficiales.

28 países han emitido diferentes disposiciones legales en materia de apoyos económicos, tanto para particulares como para empresas privadas, solamente nueve países no lo han hecho o no se reportan en espacios oficiales.

El 7 de mayo la OMS emitió una guía técnica denominada Orientación ética para el uso de recursos limitados en los servicios críticos de salud durante la pandemia de COVID-19, sin embargo, solamente nueve ${ }^{20}$ países cuentan con instrumentos guía que atienden esta guía técnica.

\section{PRincipios Éticos y eSTRATEgIAS De SALUd PÚBLICA}

\section{Transparencia}

La búsqueda en los sitios web de cada país, como un criterio para acceder a información oficial, permitió observar el nivel de transparencia en la información relativa a COVID-19 que maneja cada Estado de la región.

Básicamente hay tres tipos de estrategia de información en internet:

a) Países con información pública ordenada, pertinente y accesible mediante un solo ícono, que distingue entre instrumentos legales y la respectiva a información a la población;

b) Países con información exclusivamente dirigida a la población como recomendaciones para su cuidado, y

c) Aquellos países que no cuentan información sobre COVID-19.

El Salvador, Guatemala, Grenada, Honduras, Islas Caimán, Islas Turcos y Caicos, Ecuador, Perú y Argentina cuentan con páginas web eficientes, diseñadas ex profeso como repositorios de información sobre la emergencia en salud ocasionada por el COVID-19. Estas páginas contienen documentos oficiales, como decretos, informes, resoluciones, regulaciones y comunicados oficiales, entre otros, actualizados periódicamente.

20 Orientación ética para el uso de recursos limitados en los servicios críticos de salud durante la pandemia de COVID-19, disponible en: disponible en: https://wrwr.paho.org/es/documentos/orientacionetica-para-uso-recursos-limitados-servicios-criticos-salud-durante-pandemia. Los nueves países son Brasil, Canadá, Colombia, Cuba, Estados Unidos, Islas Caimán, Jamaica, México y Perú. 
Este libro forma parte del acervo de la Biblioteca Jurídica Virtual del Instituto de Investigaciones Jurídicas de la UNAM

Llama la atención que países en conflicto social permanente y prolongado como El Salvador y Honduras cuenten con este tipo de sitios web con tal calidad y claridad. Podría plantearse la cuestión de si para los ciudadanos de dichos países es tan fácil el acceso a internet y con ello, a los sitios mencionados.

Las páginas de los gobiernos de México y de EUA presentan características diferentes. No cuentan con una página específica y exclusiva que contenga en sí misma todos los datos antes referidos. Para el caso de México, por ejemplo, la página del Consejo de Salubridad General no presenta toda la información en una sección "inmediata" sobre COVID-19. El banner Información General sobre el nuevo coronavirus despliega una página de iconos con hipervínculos, 20 de ellos sobre higiene de manos. Si bien la mayoría de los documentos son localizables, requiere de tiempo y/o conocimiento de las áreas específicas ( $v g$. medidas legales, reglamentos, salud, economía, etc.) para su acceso.

Para el caso de EUA, la autonomía que presentan los estados, la precisión y sistematización de la información, y la diversidad de organismos interrelacionados en las mismas áreas confiere dificultades específicas. Por ejemplo, para el caso de COVID-19 en el área de la salud están involucrados, entre otros, la FDA, el Congreso, el Departamento de Salud y Servicios Humanos, los CDC, los Institutos Nacionales de Salud, el Departamento de Defensa, el de Seguridad Nacional, la OMS, las organizaciones de la sociedad civil, la industria farmacéutica y los gobiernos estatales. Así, la información existe, y nuevamente, aun con el conocimiento de las áreas y el desplazamiento entre ellas, acceder a la información toma mucho tiempo.

\section{Gobernanza}

Como ya se mencionó, las pandemias son emergencias en salud pública, que por definición son imprevistas en su presentación, impredecibles en su comportamiento y de gran impacto entre las poblaciones que afectan. La que los Estados enfrentan actualmente por COVID-19 no es la excepción. Para su control, es indispensable que los gobiernos tomen medidas oportunas, dinámicas y eficientes que se reflejen como una reducción en el impacto negativo tanto en salud como en las demás esferas de las actividades de una sociedad.

En la mayoría de los países, las medidas de seguridad sanitaria derivadas de la declaratoria de emergencia, además de las dictadas para los individuos como la higiene de manos y el distanciamiento social incluyeron, entre otras: la suspensión de actividades escolares, de actividades económicas no 
Este libro forma parte del acervo de la Biblioteca Jurídica Virtual del Instituto de Investigaciones Jurídicas de la UNAM

esenciales, de actividades laborales del estado y de actividades recreativas, todas ellas encaminadas a limitar o impedir la transmisión del virus. Otras medidas, como la cuarentena y el aislamiento fueron tomadas con la finalidad de evitar la transmisión y la posibilidad de detectar oportunamente los casos más severos.

En la región de las Américas, estas medidas fueron dictadas desde los gobiernos centrales y con aplicación simultánea para todo el país, junto con la declaratoria en la mayoría casos, a excepción de los EUA, donde derivado de la autonomía de los estados (principalmente), las medidas se tomaron en momentos diferentes y de forma más o menos heterogénea.

Entre otros países, EUA y México no emiten declaraciones de estado de excepción. Honduras es el único en hacerlo de forma radical. Otros países hacen la declaratoria de estado de excepción, estipulando medidas encaminadas principalmente a la restricción de horarios para circular fuera del domicilio y/o fuera del territorio estipulado (límites de zona o ciudad).

\section{Fusticia}

En algunos de los Estados, el número de enfermos creció de manera casi exponencial. Así, en lapsos muy cortos, los recursos en salud para la atención de los enfermos de COVID-19, en especial los equipos de protección personal como cubrebocas, guantes, batas y demás insumos desechables (algunos de los cuales se utilizan también en los pacientes hospitalizados) fueron insuficientes en un momento determinado.

Cuatro Estados de la región (EUA, Islas Caimán, Jamaica y México) emitieron algún tipo de directriz para asignación de recursos escasos en salud, especialmente para aquellos requeridos por los enfermos que requieren atención de terapia intensiva: camas en unidades de cuidados intensivos y ventiladores.

Para México, algunas de las estrategias fueron la reconversión de hospitales y la puesta en marcha del Plan DN-III de la Secretaría de la Defensa Nacional y el Plan Marina, incrementando con ello la capacidad de respuesta con un mayor número de camas de hospital y de terapia intensiva.

Sobre este tema, el caso paradigmático son los EUA, ya que, a pesar de su nivel de desarrollo económico, no ha podido resolver el problema de abasto de recursos, en especial aquellos de medicina crítica. Además de la movilización de ventiladores y camas de hospital (para el 25 de abril se habían movilizado 10,988 ventiladores y 15,700 camas hacia las zonas más afectadas, resultandos insuficientes también estos en un momento dado), 
Este libro forma parte del acervo de la Biblioteca Jurídica Virtual del Instituto de Investigaciones Jurídicas de la UNAM

fueron necesarias estrategias emitidas por los CDC para la asignación de ventiladores de tal manera que su utilización sea eficaz, eficiente y con equidad, basadas en cuatro factores:

a) Evaluación de necesidades;

b) Determinación de la capacidad de las unidades de atención para absorber ventiladores adicionales;

c) Consideraciones éticas para informar cómo estos recursos escasos son proporcionados a las unidades que puedan salvar tantas vidas como sea posible, $y$

d) Propuestas de líderes estatales y locales, expertos en legislación y ética, y de las partes interesadas.

Sin duda una medida basada en justicia social es la que corresponde a la protección de la salud y la seguridad de su personal de salud. Destaca EUA, que especificó puntualmente las medidas y equipos de protección personal de acuerdo con el nivel de exposición a riesgos durante el desempeño de sus labores. En los decretos de emergencia, se menciona la protección de profesionales de la salud en Argentina, Perú, Antigua, Belice, Brasil, Canadá, Colombia, Costa Rica, Cuba, Perú y República Dominicana.

\section{Libertad}

El impacto en salud (y en otras áreas) de cada pandemia depende del número de personas infectadas, la transmisibilidad de la infección y el espectro clínico de severidad que presentan los individuos afectados.

Para controlar este impacto, las principales medidas en salud que han repercutido en la libertad de los individuos son las disposiciones sobre la cuarentena, que tiene por objetivo evitar el riesgo de contagio y disminuir la circulación del virus, bajo la premisa de que los individuos infectados pero asintomáticos pueden transmitir la enfermedad; y el aislamiento, que se aplica a enfermos y cuyo objetivo es evitar el contagio a más personas y la vigilancia de la evolución en su estado clínico. Ecuador, El Salvador, Granada e Islas Caimán dictaron medidas de cuarentena para contactos. A excepción de EUA (que dictó procedimientos para prohibir el ingreso de viajeros procedentes de países específicos), todos los países emitieron decretos para la cuarentena de viajeros procedentes de países con alta circulación del virus en las primeras semanas de la pandemia, mientras sus fronteras estuvieron abiertas. Posteriormente Dominica, EUA, Guatemala, Honduras, Islas Tur- 
Este libro forma parte del acervo de la Biblioteca Jurídica Virtual del Instituto de Investigaciones Jurídicas de la UNAM

cos y Caicos, Jamaica y México emitieron disposiciones para cuarentena voluntaria para la población general.

Dominica, Ecuador, El Salvador, Granada, Islas Caimán e Islas Turcos y Caicos impusieron aislamiento obligatorio, mientras que EUA, Guatemala, Jamaica y México dispusieron medidas de aislamiento voluntarias.

\section{Gonclusiones}

Es posible que la transmisibilidad y el potencial agresivo de la enfermedad producida por el virus SARS-CoV-2 hayan sido subestimados en las semanas inmediatas posteriores a la detección de los primeros casos en China y otros países de Europa y EUA. Como consecuencia, la declaratoria de la situación de pandemia por COVID-19 y del estado de emergencia sanitaria (o su equivalente de acuerdo con cada país) emitido por los Estados de la región de las Américas pudieron haber sido demoradas. Una vez emitida la alerta internacional ante la pandemia, la falta (en la mayoría de los países de la región) de un protocolo claramente definido para dar respuesta a las emergencias en salud pública (como lo vincula el RSI) pudo impactar negativamente en la oportunidad y eficacia de las disposiciones legales y las acciones en salud pública de ellas derivadas.

Las disposiciones preventivas (distanciamiento social, higiene de manos, medidas de cuarentena y aislamiento, suspensión de actividades escolares, sociales, laborales y económicas) para contener y controlar la pandemia por COVID-19 han sido efectivas en muchos de los países de la región. Sin ellas, la situación indudablemente sería aún peor.

Las determinaciones para cierres de fronteras, estados de excepción y toques de queda se han aplicado heterogéneamente en cuanto a tiempo y medidas que implican. Tampoco se encontraron definiciones de cada uno de estos conceptos para buscar consenso entre ellos. Con lo anterior, el apego al Pacto de Siracusa, o falta de este, representan una oportunidad para revalorar las situaciones de excepción que justifiquen la suspensión de algunos de los derechos de los individuos en caso de emergencias en salud pública.

\section{FUENTES DE CONSUlTA}

CoHEn, Glenn et al., "Potential Legal Liability for Whitdrawing or Whithholding Ventilators During COVID-19", Fournal of the American Medical Association, vol. 323, núm. 19, 19 de mayo de 2020. 
Este libro forma parte del acervo de la Biblioteca Jurídica Virtual del Instituto de Investigaciones Jurídicas de la UNAM

Coughlin, Steven, "Ethical issues in epidemiologic research and public health practice", Emerging Themes in Epidemiology, vol. 3, núm. 1, 3 de octubre de 2006.

Consejo Económico y Social de la Organización de las Naciones Unidas. "Pacto de Siracusa", Comisión de Derechos Humanos, 28 de septiembre de 1984, 41 periodo de sesiones, tema 18, disponible en: https://undocs.org/ pdf? symbol=es $/ E / C N$. $4 / 1985 / 4$.

DEVI, Sharmila, "COVID-19 exacerbates violence against Health Workers". The Lancet no. 396, núm. 10252, p. 658, 5 de septiembre de 2020.

Hoffman, Steven et al., "Do not Violate the International Health Regulations during the COVID-19 outbreak", The Lancet, vol. 395, 29 de febrero de 2020.

Johns Hopkins University \& Medicine. Cronavirus Resouce Center. CVID19 Dashboard by the Center for Systems Science and Engineering (CSSE) at Johns Hopkins University (JHU), disponible en: https://coronavirus.jhu. edu/map.html.

LISSARDY, Gerardo, "Coronavirus: el drama del COVID-19 en Nueva York, una ciudad con las morgues repletas y hospitales de campaña", $B B C$, Neres, 8 de abril 2020, Nueva York, disponible en: https://wrerr.bbc.com/mundo/ noticias-internacional-52211307.

Oficina del alto Comisionado de las Naciones Unidas. "Las medidas de emergencia y el COVID-19: Orientaciones", 27 de abril de 2020, disponible en: https://wrere.ohchrorg/Documents/Events/EmergencyMeasures_COVID19_ES.pdf.

ORGANIZACiÓN MUNDiAL DE LA SALud, "Brote de enfermedad por coronavirus (COVID-19)", disponible en: https://werew.who.int/es/emergencies/ diseases/novel-coronavirus-2019? ?gclid=EAIaIQobChMIyoad_o6W6gIVwpfbCh1towIaEAAYASAAEgK9DvD_BwE.

ORGANIZACiÓn MUNDiAL DE LA SALUd, "Declaración sobre la segunda reunión del Comité de Emergencias del Reglamento Sanitario Internacional (2005) acerca del brote del Nuevo Coronavirus". 30 de enero de 2020, disponible en: https://wrere.who.int/es/news-room/detail/30-01-2020-statementon-the-second-meeting-of-the-international-health-regulations-(2005)-emergency-committee-regarding-the-outbreak-of-novel-coronavirus-(2019-ncov).

ORGanización Mundial de la SALud. Declaración sobre la tercera reunión del Comité de Emergencias del Reglamento Sanitario Internacional (2005) acerca del brote de enfermedad por coronavirus (COVID-19), 1o. de mayo de 2020, disponible en: https://wwrw.who.int/es/news-room/ 
Este libro forma parte del acervo de la Biblioteca Jurídica Virtual del Instituto de Investigaciones Jurídicas de la UNAM

detail/01-05-2020-statement-on-the-third-meeting-of-the-international-health-regulations-(2005)-emergency-committee-regarding-the-outbreak-of-coronavirus-disease(covid-19).

Organización Mundial de la SAlud, "Reglamento Sanitario", OMS. 2016, Ginebra.

PARMET, Wendy y SinHa, Michael. "The Law and limits of Quarentine", The New England Fournal of Medicine, vol. 382, núm. 15, 6 de junio de 2020.

Río, Carlos del y MaLAni, Preetl, "COVID-19 New Insights on a Rapidly Changing Epidemic", Journal of the American Medical Association, vol. 323, nún. 14, 14 de abril de 2020. 